\title{
Scirrhous Carcinoma Cell Invasion into the Stomach Wall Detected by Monoclonal Antibody S202: A Comparison between Immunoperoxidase and Hematoxylin-Eosin Stain
}

\author{
Takashi Yokota, Toshio Takahashi, Toshinaru \\ Yamaguchi, Kiyoshi Sawai, Akeo Hagiwara, Masataka \\ Shimotsuma, Masaki Doi, Takashi Masuko* and \\ Yoshiyuki Hashimoto* \\ The First Department of Surgery, Kyoto Prefectural \\ University of Medicine, Kyoto 602, and *Department of \\ Hygienic Chemistry, Pharmaceutical Institute, Tohoku \\ University, Sendai 980
}

Yokota, T., Takahashi, T., Yamaguchi, T., Sawai, K., Hagiwara, A., Shimotsuma, M., Doi, M., Masuko, T. and Нashimoto, Y. Scirrhous Carcinoma Cell Invasion into the Stomach Wall Detected by Monoclonal Antibody S202 : A Comparison between Immunoperoxidase and Hematoxylin-Eosin Stain. Tohoku J. Exp. Med., 1989, 157 (2), 137-144 — We used anti-scirrhous carcinoma monoclonal antibody (MAb) S202, which reacted strongly with scirrhous gastric cancer, to evaluate the depth of cancer cell invasion into the stomach wall. Sixty-eight scirrhous gastric cancer specimens were stained with the avidin-biotin peroxidase complex method using MAb S202. There were some discrepancies between the histological evaluation of the immunoperoxidase (IP) and hematoxylin-eosin (HE) staining regarding the depth of tumor invasion. In two of the $14 \mathrm{HE}$ staining cases in which carcinoma had extended as far as the proper muscular layer, IP staining revealed that the lesions had actually penetrated this layer. As well, in two of the $18 \mathrm{HE}$ staining cases in which carcinoma cells had not penetrated as far as the serosa, IP staining revealed that they had, in fact, reached the serosal surface. The invasive carcinoma cells were more easily discerned using IP staining with MAb S202 rather than using histological staining with HE. Thus, MAb S202 may be useful for precise identification of carcinoma cells __ immunohistological diagnosis; scirrhous gastric cancer; monoclonal antibody; S202

Scirrhous gastric cancer is clinically characterized by diffuse thickening and sclerosis of the gastric wall, marked hypertrophy of the mucosal folds, and erosions

Received September 30, 1988 ; revision accepted for publication January 19, 1989.

Supported in part by a Grant-in-Aid for Cancer Research from the Ministry of Education, Science and Culture, Japan, and a grant from the Ministry of Health and Welfare, Japan. 
or ulcers of the gastric wall (Iwanaga and Taniguchi 1972 ; Nagayo and Yokoyama 1974; Hiroki et al. 1986; Kanter et al. 1986; Nakamura and Saitoh 1986). The infiltrative carcinoma may grow either superficially over the surface of the mucosa or permeate the entire thickness of the wall producing a pattern known as linitis plastica. Most tumor cells grow without glandular formation. It is sometimes difficult to identify the cancer cells in the fibrous tissue, even by microscopic examination. In this study, we attempted to evaluate the precise depth of scirrhous carcinoma cell invasion into the stomach wall with immunohistochemical method, using monoclonal antibody (MAb) S202 (Yokota et al. 1987, 1988 a, b, c, 1989).

\section{Materials and Methods}

\section{Specimens}

Cases of scirrhous gastric carcinoma were selected from the diagnostic files of the Kyoto Prefectural University of Medicine. A total of 68 specimens from 68 different patients were evaluated. The depth of tumor penetration of the stomach wall was assessed from the hematoxylin and eosin (HE) stained sections according to criteria suggested by the Japanese Research Society for Gastric Cancer (1981). Histological examination of the 68 cases, diagnosed by routine pathological criteria, revealed that the cancer cells were limited to the submucosa in 3 cases, invaded the muscularis propria in 14 cases, spread to the subserosa in 18 cases and beyond the subserosa in 33 cases. After slides from each patient were reviewed, tissue blocks which contained tumor tissues were then selected. Blocks were cut into $5 \mu \mathrm{m}$-thick sections, and deparaffinized. All specimens were fixed in $10 \%$ formalin.

\section{Antibodies}

MAb S202 is secreted by a hybridoma. In this study, these hybridomas were established by the fusion of P3X63Ag8 mouse myeloma cells with splenocytes taken from a mouse immunized with the scirrhous gastric carcinoma cell line, MK-01. The hybridomas were maintained in tissue culture medium (RPMI-1640 medium supplemented with $10 \%$ fetal calf serum), and were used as the source of MAb for the immunoperoxidase (IP) assays. RPMI-1640 medium, alone, was used as a control.

\section{IP staining}

The IP assay was performed using the avidin-biotin peroxidase complex (ABC) technique (Hsu et al. 1981). The slides were incubated successively for $30 \mathrm{~min}$ at room temperature with each of the following reagents : normal horse serum; approximately $0.2 \mathrm{ml}$ of undiluted tissue culture medium containing mouse $\mathrm{MAb} ; 3 \% \mathrm{H}_{2} \mathrm{O}_{2}$ in absolute methanol for $5 \mathrm{~min}$ in order to inhibit endogenous peroxidase; biotinylated anti-mouse antibody; and $\mathrm{ABC}(1 / 150)$. The slides were rinsed for $15 \mathrm{~min}$ in phosphate buffered saline after each step. Finally, they were treated with a solution of $0.06 \%$ diaminobenzidine and $0.01 \%$ $\mathrm{H}_{2} \mathrm{O}_{2}$ in $0.5 \mathrm{M}$ Tris buffer ( $\mathrm{pH} 7.4$ ), counterstained with hematoxylin, dehydrated and mounted.

\section{Evaluation of the slides}

The MAb-incubated slides were compared with the control slides. Staining intensity was graded from 0 to $2+$ (negative to the most intense). The immunostained slides and the others treated with HE, were compared, based on their ability to demonstrate the depth of tumor penetration of the stomach wall. The estimation of the distribution and degree of positive staining of the tumors, was performed by two observers. 


\section{RESULTS}

Sixty-eight specimens were stained with MAb S202 using the ABC method. MAb S202 reacted with the carcinoma cells, resulting in strong and diffuse staining (Fig. 1), consistently judged as $2+$. Table 1 shows the results of the microscopic analysis of the depth of tumor cell penetration of the stomach wall, using slides either immunostained with MAb S202 or histologically stained with HE. In two of the 14 cases in which HE staining indicated that the carcinoma had extended as far as the proper muscular layer, IP staining revealed that the lesions had actually penetrated this layer. As well, in two of the 18 cases in which $\mathrm{HE}$ staining suggested that carcinoma cells had not penetrated as far as the serosa, IP staining revealed that they had, in fact, reached the serosal surface.

\section{Discussion}

The prognosis for patients with scirrhous gastric cancer is extremely poor due to the low incidence of early detection, and frequent recurrence of peritoneal dissemination (Iwanaga and Taniguchi 1972; Hioki et al. 1986). Results of the microscopic examination of scirrhous gastric cancer samples demonstrated that the infiltration of cancer cells was far more widespread in the intramural layer than in the mucosa (Nagayo and Yokoyama 1974 ; Nakamura and Saitoh 1986); thus, it is important to assess the histology in terms of the depth of cancerous invasion. At times, however, it can be difficult to identify scirrhous carcinoma cells microscopically, since individual malignant cells infiltrate the intramural layers of the stomach diffusely, accompanied by the intense proliferation of fibrous connective tissue.

In the present study, we used MAb S202, which was found to react with scirrhous gastric carcinoma with diffuse and strong staining, to evaluate the

TABLE 1. Determination of the depth of scirrhous gastric carcinoma cells in the stomach wall* by microscopic examination. Comparison of immunoperoxidase staining with MAb S202 and hematoxylin-eosin stain

\begin{tabular}{llcrrr}
\hline $\begin{array}{l}\text { Diagnosed } \\
\text { by HE stain }\end{array}$ & & sm & pm & ss & se \\
\hline & sm & 3 & & & \\
Diagnosed by & pm & & 12 & & \\
S202 stain & ss & & 2 & 16 & \\
& se & & & 2 & 33 \\
\hline
\end{tabular}

*The depth of cancer cell invasion into the stomach wall was classified as follows: Cancerous infiltrations limited to the submucosa $(\mathrm{sm})$, invasion into the muscularis propria $(\mathrm{pm})$, into the subserosa ( $\mathrm{ss}$ ) and beyond the subserosa (se). 


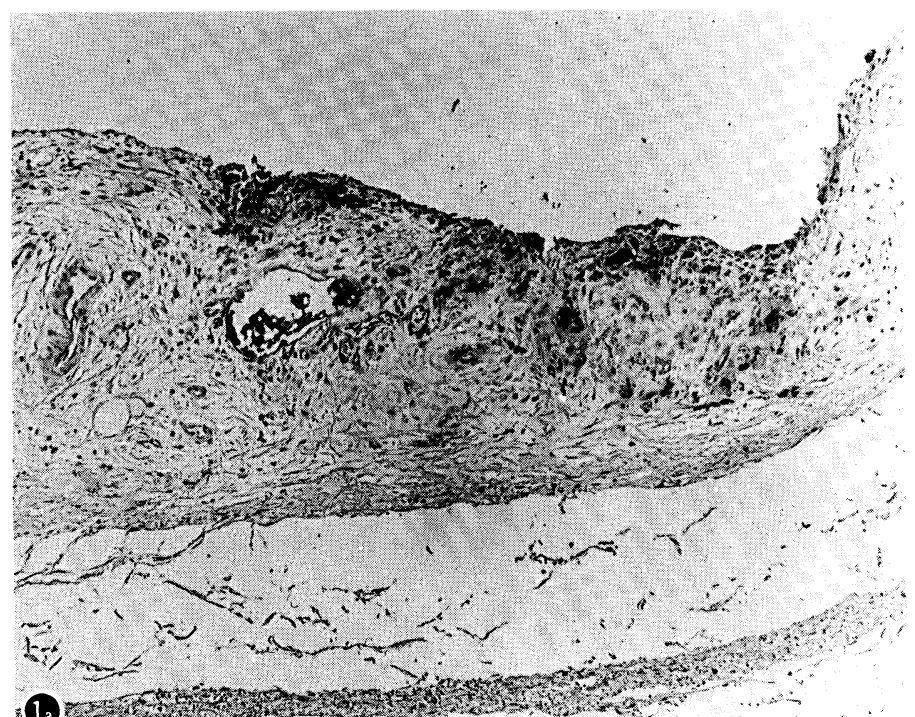

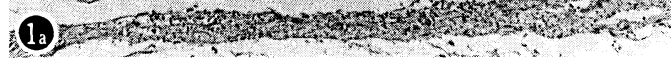

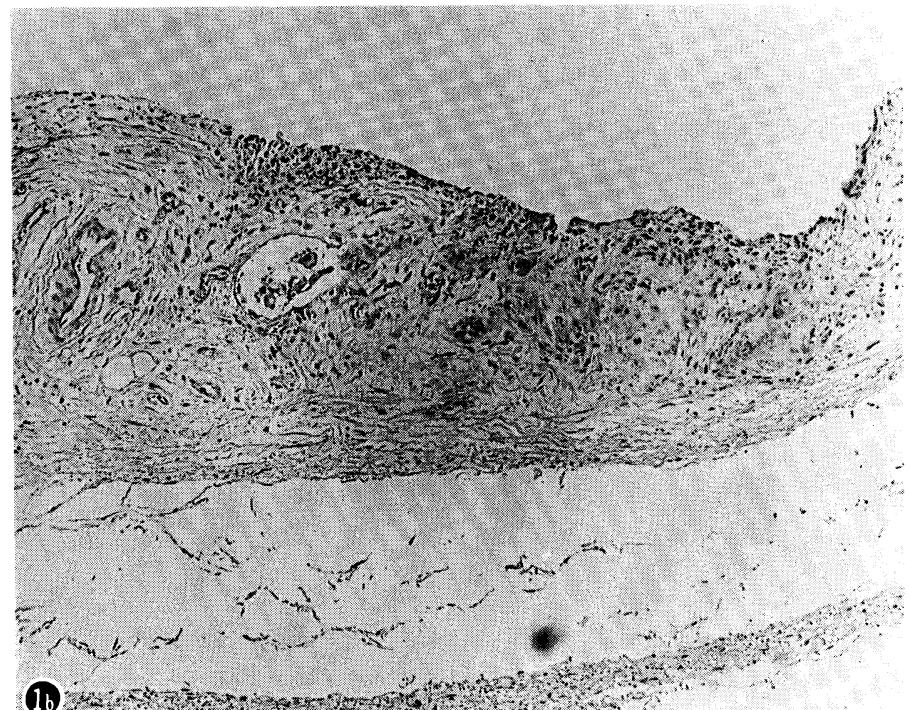

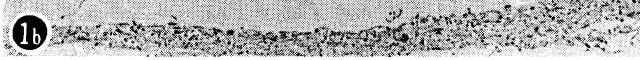

Fig. 1. (a) Immunoperoxidase staining of an adenocarcinoma sample with MAb S202. Carcinoma cells can be clearly discerned. $\times 40$. (b) Hematoxylineosin staining. $\times 40$. (c) Immunoperoxidase staining. $\times 100$. (d) Hematoxylin-eosin staining. $\times 100$.

precise depth of cancer cell invasion of the stomach wall. The antigen detected by MAb S202 is found in the cytoplasm of cancer cells, but not of inflammatory cells (Yokota et al. 1987). The invasive carcinoma cells were more easily discerned using IP staining with MAb S202 rather than using histological staining with HE. There were discrepancies between the histological findings of the IP 


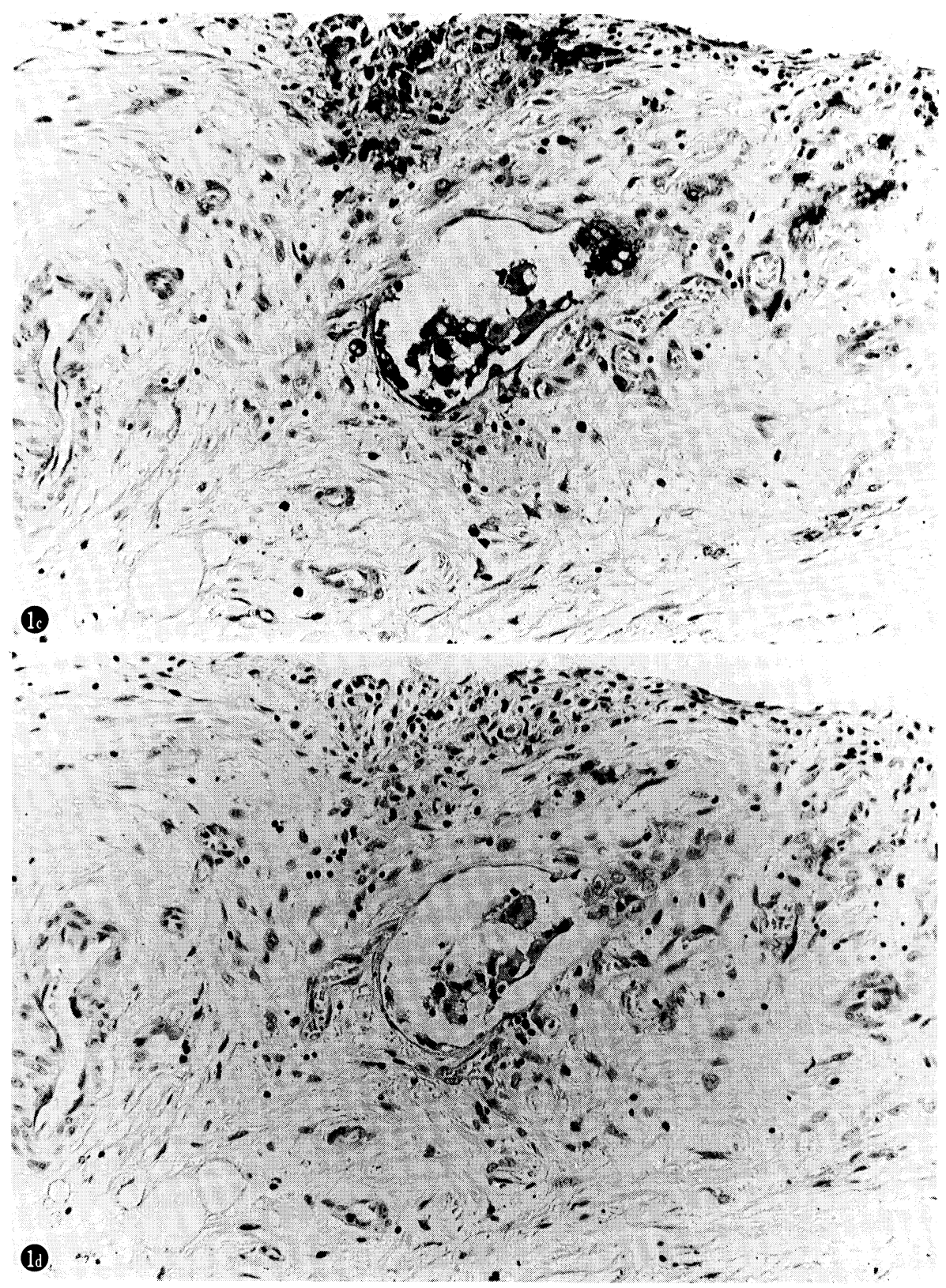

and HE staining methods regarding the depth of tumor invasion in four of the 68 cases. Carcinoma cells were detected immunochemically, and were found to be far more widespread in the intramural layer. In most cases, cells stained with $\mathrm{HE}$ could be identified as malignant by standard cytological criteria. In four cases, however, tumor cells appeared sparsely distributed against a dense, often confus- 
ing background of inflammatory cells. We found that MAb S202 highlights these single cells more reliably than HE staining. When the sections stained with $\mathrm{HE}$ were re-examined, the diagnosis of cancer was not supported by a feature consistent with carcinoma cells identified ; in another words, it could not be decided whether the cells were malignant or not by cytological criteria. In our series, MAb S202 was effective in only four cases. However, in the two cases in which malignant cells were considered to be limited to the subserosal layer on the basis of HE findings, cancer cells were detected beyond that layer using MAb S202. Adjuvant chemotherapy to discourage peritoneal dissemination is necessary once the cancer is found to extend beyond the subserosal layer; therefore, the accurate determination of the extent of the cancerous invasion is of great therapeutic and prognostic importance. The possibility that these tumor cells may not be detected with HE cannot be ignored. This may explain why some patients who underwent absolute curative surgery, and were diagnosed as cured by microscopic examination, had worse survival rates than expected.

Recently, several studies have investigated the clinical applications of immunohistochemical techniques to supplement the diagnostic information obtained by conventional cytomorphology (Heyderman and Neville 1977; Whiteside and Dekker 1979; Walts and Said 1983 ; Hockey et al. 1984 ; Bramwell et al. 1985 ; Gerdes 1985; Hausheer and Yarbro 1985 ; Johnston et al. 1985 ; Kyrkou et al. 1985 ; Lloyd et al. 1985; Chess and Hajdu 1986; Gibson and Kemshead 1987 ; Goodwin et al. 1987; Michie et al. 1987; Reiner et al. 1987; Hay et al. 1988; Kawai et al. 1988; Lyubsky et al. 1988; Stahel et al. 1988), but few have done so with gastrointestinal tumors (Piantino et al. 1986). Previously, MAb S202 was used in a rapid immunostaining procedure to identify the limit of tumor invasion during surgery (Yokota et al. 1988, 1989). The ability to discriminate between carcinoma cells and inflammatory cells was demonstrated on cryostat sections of tumor tissues. This technique permitted clear recognition of the infiltrating tumor cells at the surgical margin.

Thus, based on the reactivity of MAb S202 with all scirrhous carcinomas and the lack of staining of inflammatory cells, MAb S202 may be a useful agent for the reliable detection of scirrhous gastric carcinoma cells in the stomach wall.

\section{Acknowledgments}

We would like to thank Dr. Shuhei Ogita for his review of the manuscript.

\section{References}

1) Bramwell, M.E., Ghosh, A.K., Smith, W.D., Wiseman, G., Spriggs, A. \& Harris, H. (1985) Ca2 and Ca3 new monoclonal antibodies evaluated as tumor markers in serous effusions. Cancer, 56, 105-110.

2) Chess, Q. \& Hajdu, S.I. (1986) The role of immunoperoxidase staining in diagnostic cytology. Acta Cytol., 30, 1-7.

3) Gerdes, J. (1985) An immunohistological method for estimating cell growth frac- 
tions in rapid histopathological diagnosis during surgery. Int. J. Cancer, 35, 169171.

4) Gibson, F.M. \& Kemshead, J.T. (1987) A monoclonal antibody (FM25) that can differentiate neuroblastoma from other small round-cell tumours of childhood. Int. $J$. Cancer, 39, 554-559.

5) Goodwin, R.A., Tuttle, S.E., Bucci, D.M., Jewell, S.D., Martin, E.W. \& Steplewski, Z. (1987) Tumor-associated antigen expression of primary and metastatic colon carcinomas detected by monoclonal antibody 17-1A. Am. J. Clin. Pathol., 88, 462-467.

6) Hausheer, F.H. \& Yarbro, J.W. (1985) Diagnosis and treatment of malignant pleural effusion. Semin. Oncol., 12, 54-75.

7) Hay, F.G., Ford, A. \& Leonard, R.C.F. (1988) Clinical applications of immunocytochemistry in the monitoring of the bone marrow in small cell lung cancer (SCLC). Int. J. Cancer, Suppl. 2, 8-10.

8) Heyderman, E. \& Neville, A.M. (1977) A shorter immunoperoxidase technique for the demonstration of carcinoembryonic antigen and other cell products. $J$. Clin. Pathol., 30, 138-140.

9) Hioki, K., Nakane, Y., Imabayashi, N. \& Yamamoto, M. (1986) Surgical treatment of patients with scirrhous carcinoma of the stomach. Saishin Igaku, 41, 1041-1047. (Japanese)

10) Hockey, M.S., Stokes, H.J., Thompson, H., Woodhouse, C.S., Macdonald, F., Fielding, J.W.L. \& Ford, C.H.J. (1984) Carcinoembryonic antigen (CEA) expression and heterogeneity in primary and autologous metastatic gastric tumours demonstrated by a monoclonal antibody. Br. J. Cancer, 49, 129-133.

11) Hsu, S.M., Raine, L. \& Fanger, H. (1981) Use of avidin-biotin-peroxidase complex $(\mathrm{ABC})$ in immunoperoxidase techniques: A comparison between $\mathrm{ABC}$ and unlabeled antibody (PAP) procedures. J. Histochem. Cytochem., 29, 577-580.

12) Iwanaga, T. \& Taniguchi, H. (1972) Histological changes of gastric scirrhous carcinoma in reference to its growth. Jpn. J. Cancer Clin., 18, 466-472. (Japanese)

13) Japanese Research Society for Gastric Cancer (1981) The general rules for the gastric cancer study in surgery and pathology. Jpn. J. Surg., 11, 127-139.

14) Johnston, W.W., Szpak, C.A., Lottich, S.C., Thor, A. \& Schlom, J. (1985) Use of monoclonal antibody (B72.3) as an immunocytochemical adjunct to diagnosis of adenocarcinoma in human effusions. Cancer Res., 45, 1894-1900.

15) Kanter, M.A., Isaacson, N.H., Knoli, S.M. \& Nochomovitz, L.E. (1986) The diagnostic challenge of metastatic linitis plastica. Am. Surg., 52, 510-513.

16) Kawai, T., Torikata, C. \& Suzuki, M. (1988) Immunohistochemical study of pulmonary adenocarcinoma. Am. J. Clin. Pathol., 89, 455-462.

17) Kyrkou, K.A., Iatridis, S.G., Athanassiadou, P.P., Athanassiadis, P.P. \& Mandragos, C.E. (1985) The cytologic application of carcinoembryonic antigen for the discrimination of malignant from benign serous effusions. Cancer Detect. Prev., 8, 247-254.

18) Lloyd, R.V., Schmidt, K., Blaivas, L., Mccoy, J.P. \& Wilson, B.S. (1985) A rapid immunostaining method utilizing preformed antibody-avidin-biotin-peroxidase complexes. Am. J. Clin. Pathol., 83, 636-639.

19) Lyubsky, S., Madariaga, J., Lozowski, M., Mishiriki, M.Y., Schuss, A., Chao, S. \& Lundy, J. (1988) A tumor-associated antigen in carcinoma of the pancreas defined by monoclonal antibody B72.3. Am J. Clin. Pathol., 89, 160-167.

20) Michie, S.A., Spagnolo, D.V., Dunn, K.A., Warnke, R.A. \& Rouse, R.V. (1987) A panel approach to the evaluation of the sensitivity and specificity of antibodies for the diagnosis of routinely processed histologically undifferentiated human neoplasms. Am. J. Clin. Pathol., 88, 457-462.

21) Nagayo, T. \& Yokoyama, H. (1974) Scirrhous carcinoma occurring in the corpus (body) of the stomach. Acta Path. Jpn., 24, 797-814.

22) Nakamura, K. \& Saitoh, Y. (1986) Clinicopathological aspects of scirrhous car- 
cinoma of the stomach. Saishin Igaku, 41, 951-959. (Japanese)

23) Piantino, P., Andriulli, A., Gindro, T., Pecchio, F., Masoero, G., Cavallini, G., Naccarato, R. \& Dobrilla, G. (1986) CA19-9 assay in differential diagnosis of pancreatic carcinoma from inflammatory pancreatic diseases. Am. J. Gastroenterol., 81, $436-439$.

24) Reiner, A., Reiner, G., Spona, J., Teleky, B., Kolb, R. \& Holzner, J.H. (1987) Estrogen receptor immunocytochemistry for preoperative determination of estrogen receptor status on fine-needle aspirates of breast cancer. Am. J. Clin. Pathol., 88, 399-404.

25) Stahel, R.A., O’Hara, C.J., Waibel, R. \& Martin, A. (1988) Monoclonal antibodies against mesothelial membrane antigen discriminate between malignant mesothelioma and lung adenocarcinoma. Int. J. Cancer, 41, 218-223.

26) Walts, A.E. \& Said, J.W. (1983) Specific tumor markers in diagnostic cytology. Acta Cytol., 27, 408-416.

27) Whiteside, T.L. \& Dekker, A. (1979) Diagnostic significance of carcinoembryonic antigen levels in serous effusions. Acta Cytol., 23, 443-448.

28) Yokota, T., Takahashi, T., Yamaguchi, T., Kitamura, K., Masuko, T. \& Hashimoto, Y. (1987) Monoclonal antibodies against human scirrhous carcinoma of the stomach. Gastroenterol. Jpn., 22, 565-570.

29) Yokota, T., Takahashi, T., Yamaguchi, T., Sawai, K., Otsuji, E., Kitamura, K., Yamane, T. \& Fujita, Y. (1988a) Histological diagnosis of scirrhous carcinoma of the stomach using monoclonal antibody S202. Gastroenterol. Jpn., 23, 9-12.

30) Yokota, T., Takahashi, T., Yamaguchi, T., Sawai, K., Otsuji, E., Kitamura, K., Suzuyama, H., Yamane, T. \& Fujita, Y. (1988b) A rapid immunostaining method for scirrhous gastric cancer during surgery using a monoclonal antibody. Jpn. J. Surg., 18, 232-234.

31) Yokota, T., Takahashi, T., Yamaguchi, T., Sawai, K., Shimotsuma, M., Doi, M., Masuko, T. \& Hashimoto, Y. (1988c) Localization of antigen defined by antiscirrhous gastric carcinoma monoclonal antibody S202 in fixed human cancer tissue. Gastroenterol. Jpn., 23, 619-623.

32) Yokota, T., Takahashi, T., Yamaguchi, T. \& Sawai, K. (1989) A rapid immunohistologic method for determining the limit of cancer invasion at the surgical margin of scirrhous carcinoma of the stomach during surgery. Am. J. Clin. Pathol., 91, $187-190$. 